\title{
Dynamical model for gamification of learning (DMGL)
}

\author{
Jung Tae Kim • Won-Hyung Lee
}

Published online: 7 August 2013

(C) The Author(s) 2013. This article is published with open access at Springerlink.com

\begin{abstract}
The purpose of this paper is to hypothesize 'Dynamical model of educational effectiveness for the gamification of learning, and to widely announce a pure and right function of game through our model. For the theoretical contribution of gamification, we propose a dynamical model of game based learning that aims to maximize educational effectiveness that correlates with the four main primary factors (curiosity, challenge, fantasy and control). The main idea of this model is based on the correlations of four factors which originating from learning games which are built on the foundations of separate theories: 1) Game Design Features 2) Key Characteristics of a Learning Game 3) a theory of educational environment design known as the ARCS (attention, relevance, confidence, and satisfaction) and 4) the theoretical background of gamification labeled the MDA(mechanics, dynamics and aesthetics) framework. We created a sigmoidal equation for the educational effectiveness of Gamification by analyzing and correlating these factors. Through this dynamical model we will show that the effectiveness of the gamification of learning is educationally superior to traditional ways of learning in specific setting, after an elapsed adaptive time period with reasonable relationship of the four primary factors.
\end{abstract}

Keywords Game · Gamification · Game based learning $\cdot$ GBL $\cdot$ Learning game

\section{Introduction}

Recent technological advances have put more people into cyberspace than ever before. Increasing amounts of people are looking to the virtual world to participate in society, be social, and carry out basic market transactions. Modern people are shopping online, talking online, dating online, working online, volunteering online, and learning online more and more frequently. Due to the rapid growth of high speed internet, smart phones and SNS, digital games have become an integral component of human socialization reaching beyond the realm of pure entertainment, evolving into an excellent tool for educational effectiveness, and even proudly accepted as an art form. U.S. Supreme Court has characterized 'digital games' thusly, 'Like protected books, plays,

\footnotetext{
J. T. Kim $(\bowtie) \cdot$ W.-H. Lee

Department of Image Engineering (Game), Graduate School of Advanced Imaging Science, Multimedia \& Film, Chung-Ang University, 503, Chung-Ang Cultural Arts Center,

84, Heukseokro, Dongjak-Gu, Seoul 156-756, Republic of Korea

e-mail: game3651@gmail.com

W.-H. Lee

e-mail: whlee@cau.ac.kr
} 
and movies, they communicate ideas through familiar literary devices and features distinctive to the medium" [2], just like other art forms. Today, the largest games employ hundreds of artists to craft the game's sensory experience, but even simple games can make an artistic statement, reinforcement a brand, or convey an emotion. Games are an art of experience [28]. Despite the progress of digital gaming overall, in some countries, previously held negative preconceptions of gaming have led to people to not only dismissing its pure and right function, but also believing that games lead to a dysfunctional lifestyle. Take the case of South Korea, under recently established Korean statutes, a law known as the Shutdown Law [19], aka the Cinderella Law, bars children under age 16 from playing online games between midnight and 6:00 am due to government fears of children's over-immersion in the online activity.

As a whole, however, gaming as a movement has been gaining recognition by the general population as a greater instrument than its original conception. Games have entered into the arena of learning games in areas such as language, mathematics, science, computers, as well as serious game sectors [1] that cover medical instruction, fire-fighting and military training, and flight and drive simulation. With this development and broader acceptance, the pure and right functions of games are gaining expanded adoption in non-game applications. Currently, we see global companies such as Amazon.com, American Airlines, Apple, Facebook, McDonald's, Nike and Starbucks aggressively structuring marketing strategies with these game mechanics as a basis [11, 20, 28, 34]. Having this focus on gaming, the new term gamification emerges, which has been defined as "the use of game design elements, characteristic for games, in nongame contexts" [8]. In other words, the concept of applying game-design thinking to non-game applications has gained common acceptance in everyday activity. The idea of gamification has spawned an intense public debate as well as numerous applications: ranging across multiple fields, including productivity, finance, health, education, sustainability, as well as news and entertainment media. Consequently, the movement in the gaming industry is more active than at any other time and ripe for studying the deeper specifics and the systems involved. Even with this fast paced change, the concept of gamification still holds to the central idea of learning games, serious games, or funware [31,34]. Therefore, the main goal of gamification is to encourage greater engagement in people and aiding in creating richer experiences in everyday life events through game mechanics and most importantly, with more enjoyment.

There may be fewer established studies on gamification to consider because of its relatively short history. However, a substantial amount of research has shown an extremely positive outcome from game based learning (GBL) [24-26]. Additionally, studies about well organized GBL settings revealing the beneficial effects of educational research are underway $[3,6,10,16,18,23,27]$.

In this article, we hypothesize four primary factors as constants and develop them with respect to time. In the future, we will substantively verify our dynamical model through systematizing. Also we will define relative constants as the absolute value of the constant by statistical experiments. For purposes of this study, the term 'gamification of learning' has the same meaning as 'game based learning' or 'learning game'. By vitalizing the research of gamification and announcing a pure and right function of game to the public, it is possible to foresee a universal application to nearly every aspect of life: gamification of business, gamification of education, gamification of finance, gamification of fitness, gamification of marketing, gamification of medical, gamification of military, and gamification of everything.

\section{Related works}

In this paper, for the theoretical contribution of gamification, we propose a dynamical model of GBL that aims to maximize educational effectiveness that correlates with the four main primary 
factors. We aspire to contribute to the development in theoretical ideas supporting gamification from a dynamical model. Additionally, we desire to see a pure and right function of game blending into one's everyday life by applying gamification based on this model. The purpose of this paper is to hypothesize 'Dynamical model of educational effectiveness for the gamification of learning, and to widely announce a pure and right function of game through our model. From educational effectiveness to other all kinds of field through gamification, we want to contribute to the theoretical improvement of gamification.

For this goal, we will analyze precedent theories and research about the main features of digital games, specifically focusing on learning games. First, we work on Game Design Factors (GDF) which are general answers for 'What features make digital games so engaging?' Second, we look over definitions and concepts of Key Characteristics of a Learning Game (KCLG). Third, we treat briefly about the Elements of Educational Environment Design: The ARCS (attention, relevance, confidence, and satisfaction) model of motivational design. Fourth, we also look into 'Basic Elements of Gamification': MDA(mechanics, dynamics and aesthetics) framework. Lastly, we are going to analyze the interrelation of dozens of elements from GDF, KCLG, MDA and ARCS using our empirical intuition, and then extract four Primary factors for Educational Effectiveness through gamification of learning. By using four primary factors as constants on hypothetical equation, we propose "Dynamical Model for Gamification of learning".

\subsection{What features make digital games so engaging?: GDF, gameplay and game balance}

\section{"What features make digital games so engaging?"}

Generally, game designers and experienced gamers answer the question with variations of the following: A bunch of cool features, A lot of fancy graphics, A series of challenging puzzles, An intriguing setting and story [29]. This paper agrees with that notion and defines these four qualities as principal Game Design Features (GDF) which help answer the question, "what makes game more game-like". GDF makes players willingly immerse themselves into the world of digital games solely based on a superficial examination. Even though GDF represents essential digital game factors, a few researchers, especially game designers working in the gaming industry, emphasize "gameplay" and "game balance" as the most important features of all. 'Gameplay' as defined by most game professionals is characterized by cool features such as 'a series of interesting choices' (Sid Meier mentioned), a surprise and delight factor [29], interactive aspects, and distinct features from the graphics and sound effects [7]. Also 'game balance' is just a step of postproduction in game development procedures that comes after all game design features have been finished, so it is better to exclude 'gameplay' and 'game balance' from GDF in this paper.

\subsection{Key characteristics of a learning game: KCLG}

Historically, intrinsic motivation is the most remarkable theory to come out of all the research on what makes things, especially digital games, fun. Thomas Malone (1980) proposed three essential characteristics for computer games: challenge, curiosity, and fantasy. By analyzing dozens of computer games heuristically, these three components were the key elements of his response to the question "What makes things fun to learn?" [21]. (1) Challenge is created by having clear, fixed goals that are relevant for the learner. Uncertain outcomes provide challenge by offering variable difficulty levels, hidden information, and randomness. (2) Curiosity exists in two different forms: sensory curiosity and cognitive curiosity. Audio and visual effects, particularly, in computer games may enhance sensory curiosity. (3) Malone defines fantasy as an environment that 'evokes mental images of things not present to the senses or within the actual experience of the person involved.' It encompasses both the emotions and the logical thought processes of the 
learner. Several years later, Malone and Lepper(1987) added "control", one more very crucial concept of a game design system, to the original three characteristics and defined all four features as "key characteristics of a learning game" [22]. (4) Control is experienced as feelings of selfdetermination and command on the part of the learner. The ingredients of contingency, choice, and power contribute to the control feature of the learning experience. Now, KCLG persuasively has established themselves as main features of learning games [20].

\subsection{Elements of educational environment design: the ARCS model of motivational design}

Many GBL Studies have utilized the ARCS Model(attention, relevance, confidence, and satisfaction) of motivational design [17] to evaluate GBL's motivational stimuli for learners' performance. Recently, researchers applied ARCS modeling to guiding the design of web-based courses [4]. ACRS Model: (1) Attention refers to the learner's response to perceived instructional stimuli provided by the instruction. (2) Relevance helps learners associate their prior learning experience with the given instruction. (3) Confidence stresses the importance of building a learners' positive expectation towards their performance on the learning task. (4) Satisfaction comes near the end of the learning process when learners are allowed to practice newly acquired knowledge or skills. Currently many scholars are applying the ARCS Model to the Educational Design for Learning Games.

\subsection{Basic elements of gamification: MDA framework}

Gamification accepts MDA Framework based on game design theory [8, 9, 33]. It consists of three concepts (mechanics, dynamics and aesthetics) which relate between game designer and game users [15]. MDA Frameworks: (1) Mechanics is related to Game System which describes the particular components of the game, at the level of data representation and algorithms. Mechanics make up the functioning components of the game: Points, Levels, Leader-boards, Badges, Challenge/Quests, On-boarding, Engagement Loop, Virtual Goods, Items, etc. (2) Dynamics describes the run-time behavior of the mechanics acting on player inputs and other outputs over time. (3) Aesthetics describes the desirable emotional responses evoked in the player, when player interacts with the game system.

Aesthetics is very closely related to Surprise, satisfaction, Delight, Envy, Honor, connection, etc. Therefore, it is meaningful to search for a relationship between other game features and MDA since it strengthens the theoretical basis of gamification.

\subsection{Four fundamental primary factors for DMGL}

This section defines four fundamental primary factors for our hypothetical model by analyzing all the correlations among principal Game Design Features (GDF), Key Characteristics of a Learning Game (KCLG), ACRS Model and MDA Framework. Even though theoretically they are not perfect yet, we wish to resolve the comprehensive factors in applying our dynamic model.

\subsubsection{GDF vs. KCLG}

First considering the GDF, while it is difficult to recognize a correlation between GDF and ARCS or MDA, we can find intuitively the close relation between GDF and KCLG. When matching the components of GDF with KCLG respectively, the results are: (1) A series of 'challenging puzzles' is synonymous with 'challenge' which is a main concept of intrinsic motivation in KCLG. (2)An 'intriguing setting and story' is closely related to 'curiosity' which is the most critical intellection in 
KCLG intrinsically. (3) 'Splendid fancy graphic components' along with pleasing sound can be a catalyst for arousing the user's imagination culminating in a feeling of 'fantasy'. (4) The more cool features, the better players can sink into gameplay experience. Therefore, players try to enjoy all the features from corner to corner and dominate the game thoroughly with maximum controllability. So it is not wrong to state that A bunch of 'cool features' can be associated with 'control' in KCLG.

\subsubsection{ARCS vs. KCLG}

In the same context, when we try to find relativeness between ARCS and GDF or MDA, it is not as easy to correlate, but we find that both ARCS and KCLG each have a matching component. That is; (1)We can regard 'attention' as 'curiosity' because these two features are concerned with the learners' attraction in a manner of speaking. When learners are stimulated by intellectual curiosity, the degree of attention will be high and vice versa. (2) Relevance is closely related to new educational information based on prior knowledge. It bears a strong likeness to level of difficulty and goal attainment of 'challenge' in KCLG. (3) Confidence is the player's expectation that they can achieve success. Therefore it can determine whether the player can control freely and dominate the game or not. (4) Satisfaction is related to the player's mental state when he/she achieves the mastery of aimed goals. Players can attain an unreal, visionary, and fantastic feeling (fantasy), when he makes an all-out effort to achieve the dreamlike goal in the game.

\subsubsection{MDA vs. KCLG}

We face a bit more complexity when piecing out the relationship between MDA with GDF or ARCS or KCLG. We can recognize a correlation between MDA and KCLG, but establishing connections with GDF or ARCS is more problematic and true correlations are not realistic. In this case, we can find that features in MDA are related to two or more elements in KCLG only. When matching features of MDA with KCLG respectively, the results are: (1) As we already recognized in this paper, game mechanics are mainly related to level of difficulty. This level of difficulty is the main concept of 'challenge', so we have to pay attention to this factor. Additionally, challenge is created from time pressure and opponent players. At last, we conclude that challenge in KCLG is related to both 'mechanics and dynamics'. (2) Curiosity is not only a crucial component derived from 'game aesthetics', but also can be evoked by an element like a reward schedule which is a component out of game dynamics that depends on the lapse of time. In between game 'aesthetics and dynamics', we can say that curiosity carries out a great role in the gamification of learning. (3)The strongest emotional factor in game aesthetics can be regarded as 'fantasy' which is related to conceptual images evoked by storytelling, audio and visual effects. Fantasy also is intimately related to reward and feedback in game mechanics. So, we can recognize that fantasy retains a close relation to 'aesthetics and mechanics'. (4) As mentioned above, MDA correlates to three factors (challenge, curiosity, fantasy) in KCLG. Control, the remaining factor in KCLG, is closely related to gameplay, so it covers all of the MDA Framework.

To sum up, we can depict the diagram by placing all features interlinked together. As analyzed above, KCLG(challenge, curiosity, fantasy, control) covers all of GFC, MDA, and ARCS Model. Finally, the four fundamental primary factors can be extremely effective in implementing educational gamification. We acknowledge that this hypothesis is open to dispute. In the near future we will make more logical connections among each feature Fig. 1. 


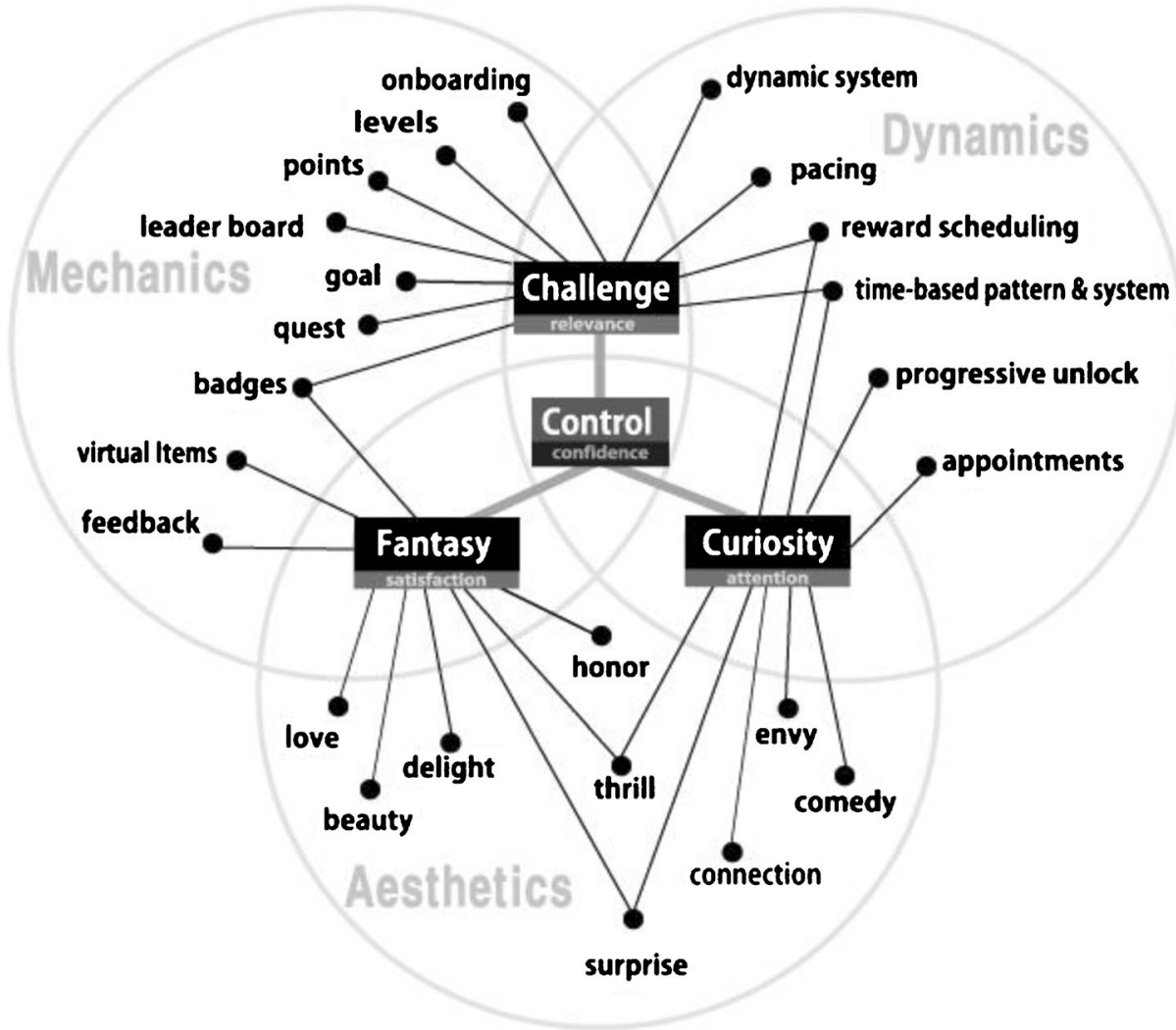

Fig. 1 Fundamental primary factors for DMGL

\section{Hypothesis (DMGL, dynamical model for gamification of learning)}

It is very meaningful to keep an eye on how the effectiveness curve goes up, and to grasp the type of functional relationship that exists between each of the primary factors that optimized educational effectiveness in gamified environments. For the purpose of finding the correlations between the aforementioned four primary factors of game design theory, we intend to set up an equation of educational effectiveness for the gamification of learning. From this dynamical model, it is reasonable to infer that the educational effectiveness can be changeable through manipulation of the four primary factors.

\subsection{Traditional way of learning vs. gamification of learning}

What's the difference between in the educational effectiveness of the gamification of learning in comparison to the traditional learning methods? First, we have to discuss the progress of achievement with respect to time. Achievement (skill or knowledge) can be displayed as a linear equation with respect to time (or effort) in traditional learning (i.e. using textbook, white board, human instructors, face-to-face classroom and so on). In general, it may look like the achievement graph is increasing in the beginning, and does not increase anymore from that point. It shows that traditional learning cannot keep up with continuing concentration and results in a limited educational effectiveness [12]. 


\subsection{Dynamical model for the gamification}

The core idea of the model for educational effectiveness through Gamification initiates the comparison with an assumption of educational effectiveness of traditional learning. Since the limitation of the traditional way of education exists in class contents, textbook, human instructor, classroom, and so on, assume that the educational effectiveness of the traditional way is solid but steady which is why it is assigned a constant value, $\boldsymbol{E}_{\boldsymbol{T} \boldsymbol{w}}$. Because of the four primary factors of game based learning which are Challenge, Fantasy, Control, and Curiosity, the assumption of the educational effectiveness through Gamification is more dynamical than the traditional way.

To be motivated by the game based learning, the dynamical model initially starts with a lower educational effectiveness than the traditional way. This lower starting point takes into consideration the adaptation time required to use the game initially. Thereafter the educational effectiveness increases rapidly and exceeds the educational effectiveness of traditional learning. Finally, the educational effectiveness will converge to a stable fixed point. Hence the educational effectiveness through Gamification can be denoted as a function of time, $x(t)$. The Fig. 2 represents the idea. Based on the assumption above, at the initial stage, the rate of change of educational effectiveness with respect to time is proportional to $x(t), \frac{d}{d t} x(t) \approx G x(t)$, where $G$ is the growth rate of educational effectiveness through Gamification, and $x(t)$ will converge on a learning capacity $L, \frac{d}{d t} x(t)=0$ at $x(t)=L$. The mathematical expression of the assumption is given by

$$
\frac{d}{d t} x(t)=G x(t)\left(1-\frac{x(t)}{L}\right)
$$

The Eq. (1) is identical to the Verhulst model for growth of human populations [14, 30, 32] and the Eq. (1) is used to describe experimental data collection [13] and the growth of bacteria populations of Paramecium aurelia and Paramecium Caudatum [5]. Consequently, the assumption of educational effectiveness follows the population growth model. Assume that the idea represents the $x(t)$ is a sigmoidal curve so that the educational effectiveness function through Gamification can be established as a sigmoidal equation. The equation set as in general form which is given by

$$
x(t)=\frac{a}{b+c e^{-d(t-k)}},
$$

Where $a, b, c, d$, and $k$ are non-negative constants. The analytical analysis and comparison with Eq. (1) make the constants $G, L, a, b, c, d$, and $k$ valuable. The first derivative of the Eq. (2) with respect to time is

$$
\dot{x}(t)=\frac{d}{d t}\left(\frac{a}{b+c e^{-d(t-k)}}\right)=\frac{a c d e^{-d(t-k)}}{\left(b+c e^{-d(t-k)}\right)^{2}} .
$$

Since the function $x(t)$ always has a positive value, the Eq. (2) can be simplified as $c e^{-d(t-k)}=\frac{a}{x(t)}-b$.

Substitute the results into Eq. (3) then

$$
\dot{x}(t)=d x(t)\left(1-\frac{b}{a} x(t)\right) .
$$

Comparison can be made of Eqs. (1) and (4) with the constant $d$ as the growth rate of educational effectiveness through Gamification, $G$. Since the Control suggests that if the user can dominate the game, more time will be spent in the game, $d$ can be proposed as the Control in this 


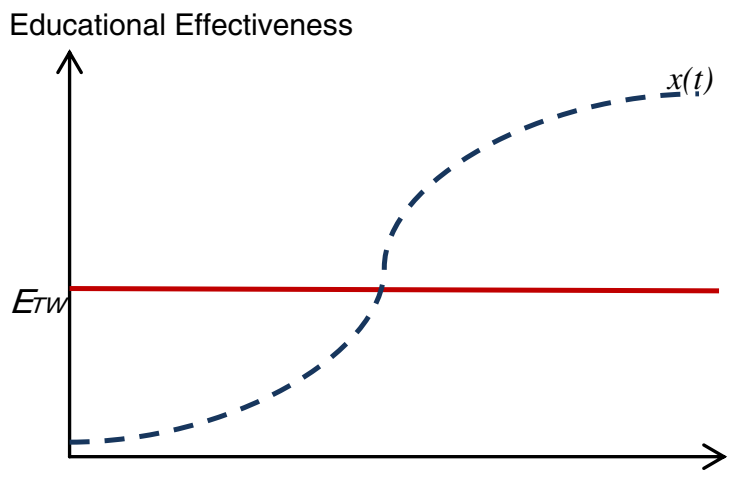

Time, $\mathrm{t}$

Fig. 2 The $\boldsymbol{E}_{\boldsymbol{T} W}$ denotes stable value of the educational effectiveness of the traditional way of education

model. The reciprocal of $\frac{b}{a}, \frac{a}{b}$, is learning capacity, $L$, in Eq. (1). Assume that the relatively high Challenge and relatively low Fantasy reduce the rate of change of educational effectiveness with respect to time respectively. So, $b$ and $a$ are proposed as Challenge and Fantasy respectively. Note the inflection point of the Eq. (2) given by

$$
(t, x(t))=\left(\frac{1}{d} \ln \frac{c}{b}+k, \frac{a}{2 b}\right) .
$$

To acquire $\ddot{x}(t)>0$ when $t>0$, the value of $t$ at inflection point, $\frac{1}{d} \ln \frac{c}{b}+k$, needs to be positive. So that the following condition, $c>b$, is obtained. The condition, $c>b$, states that the constant, $c$, is relatively higher than the constant, $b$, to keep accelerating the educational effectiveness. Since the constant, $b$, is Challenge, the assumption of the constant, $c$, as Curiosity is understandable. If the Curiosity is relatively higher than the Challenge, the educational effectiveness will be increased rapidly. Since the relatively lower Challenge makes the time of converge, $\frac{1}{d} \ln \frac{c}{b}+k$, longer to approach the stable fixed point, $\frac{a}{b}$. If the converge time longer, then motivation will be reduced. Therefore, the ratio of the Challenge and the Fantasy, $\frac{b}{a}$, has efficient range. To consolidate the idea of the coefficients, $a, b, c, d$, and $k$, the relationship between $x(t)$ and $\boldsymbol{E}_{\boldsymbol{T} W}$ should be considered. To take the advantage of the educational effectiveness through the Gamification needs to satisfy the area of $\boldsymbol{E}_{\boldsymbol{T} W}$ from $t=0$ to $t=t^{*}$ must be less than the area of $x(t)$ from $t=0$ to $t=t^{*}$. Then the result given by

$$
\boldsymbol{E}_{T W} \mathrm{t} *<\frac{a}{b}\left[t^{*}+\frac{1}{d} \ln \left(\frac{b+c e^{-d t^{*}}}{b+c}\right)\right] .
$$

\subsection{The summarization of the coefficients}

The summary of the coefficients is that: (1) $d$ is the growth rate of educational effectiveness through gamification and can be considered as the Control in this model. (2) $b$ and $a$ are denoted as Challenge and Fantasy respectively and the value of $\frac{b}{a}$ is relatively low but not too low for decreasing the converge time. (3) $c$, is relatively higher than the constant, $b$, to keep accelerating the educational effectiveness and the constant, c, as Curiosity. (4) $k=0$ at this point so that $x(0)=\frac{a}{b+c}$. 


\section{Conclusion and future work}

Game elements play substantial roles not only in education but also in numerous non-gaming applications on pc's, smart phones, and tablets. These kinds of activities also can be defined as gamification. Right now, it is in a very nascent stage, so this paper mostly hypothesized a dynamical model related to precedent studies of GBL, not gamification. For this hypothesis, we analyzed the main design elements of digital games, the intrinsic motivational theory, MDA Framework and ARSC Model. With the intent of hoping to see a wide use, we coined the term "gamification of learning" rather than using Game Based Learning or Learning Game, while applying the theoretical background of GBL to create the dynamical model. Four Fundamental primary factors derived from intrinsic motivation are the most important concept in the gamification of learning as well as the main features of making digital games more engaging. We created a sigmoidal equation for the educational effectiveness of Gamification by analyzing and correlating these factors. Dynamical model for educational effectiveness of gamification is in contrast with traditional learning which has a solid and steady educational effectiveness. Our model produced an equation for growth that mirrors human population, in which the learning curve is drastically increased after an initial time period where the learner has adapted to the gamified learning process. It is possible to control the adaptation time and slope of the four core factors as meaningful constants. This control implies that we can find the most optimized circumstances for the educational effectiveness of gamification of learning in accounting for factors such as gender, age, tendency, and other personalized qualities. Thus, we can create the theoretically ideal game with the most educational effectiveness under conditions of reducing the adaptation time and increasing the angle of the slope.

In upcoming work, we will systemize the dynamical model through substantive verification. First we will study to make measurements for each factor and define absolute value for relative constants through statistical experiment and analysis. Second, we will propose an equation including sex, age, tendency, etc. Third, we will study to expand our dynamical model to focus on personalized motivation to a model that includes interpersonal factors such as cooperation, competition etc. Finally, we will focus on reconsolidating the dynamical model for the theoretical foundation of gamification that can positively affect aspects of society including but not limited to Health, Environment, and Government.

Open Access This article is distributed under the terms of the Creative Commons Attribution License which permits any use, distribution, and reproduction in any medium, provided the original author(s) and the source are credited.

\section{References}

1. Abt CC (1970) Serious games, vol. xvi. Viking, New York, p 176

2. Brown V (June 27, 2011) EMA/ESA, No. 08-1448, slip opinion, U.S. Supreme Court

3. Carron T, Marty JC, Heraud JM (2008) Teaching with game-based learning management systems: exploring a pedagogical dungeon. Simulation \& Gaming

4. ChanLin LJ (2009) Applying motivational analysis in a web-based course. Innov Educ Teach Int 49(1):91-103

5. De Vries G, Hillen T, Lewis M, Li M, Muller J, Schonfisch B (2003) A short course in mathematical and computational biology. SIAM

6. Deb S (March, 2012) Distance learning in developing countries through multimedia technology using mobile devices. Int J Educ Learn 1(1)

7. Definition of gameplay: Wikipedia, Oxford Dictionaries. (British \& World English)

8. Deterding S, Dixon D, Khaled R, Nacke L (2011) From game design elements to gamefulness: defining gamification. In: Proceedings of MindTrek

9. Deterding S, Khaled R, Nacke L, Dixon D (2011) Gamification: toward a definition. In: CHI 2011 Gamification Workshop 
10. Ebnera M, Holzinger A (2007) Successful implementation of user-centered game based learning in higher education: an example from civil engineering. Comput Educ

11. Fields T, Cotton B (2011) Social game design: monetization methods and mechanics

12. Francis DJ, Shaywitz SE, Stuebing KK, Shaywitz BA, Fletcher JM (1996) Developmental lag versus deficit models of reading disability: a longitudinal individual growth curves analysis. J Educ Psychol 88(1):3-17

13. Gause GF (1969) The struggle for existence. Hafner

14. Hillen $\mathrm{T}$ (2003) Applications and limitations of the verhulst model for populations. University of Ualberta, pi, issue6, pp. 19-20

15. Hunicke R, LeBlanc M, Zubek R (2004) MDA: a formal approach to game design and game research

16. Kapp KM (2012) The gamification of learning and instruction: game-based methods and strategies for training and education, pp. 75-103

17. Keller JM. Strategies for stimulating the motivation to learn. Performance and Instruction (1987a), IMMS: Florida State University. (1987b)

18. Kiili K (2005) Digital game-based learning: towards an experiential gaming model. Internet High Educ

19. Youth Protection Law (Shutdown Law), no. 23, South Korea. (November 20, 2011)

20. Lepper MR, Cordova DI (1992) A desire to be taught: instructional consequences of intrinsic motivation. Motiv Emot

21. Malone TW (1980) What makes things fun to learn? a study of intrinsically motivating computer games. Technical report, Xerox Palo Alto Research Center

22. Malone TW, Lepper MR (1987) Making learning fun: a taxonomy of intrinsic motivations for learning. In: Snow RE, Farr MJ (eds) Aptitude, learning and instruction III

23. Nagarajan P, Wiselin JG (December, 2010) Online educational system (e- learning). Int J u- and e- Serv Sci Technol 3(4)

24. Park H (March, 2012) Relationship between motivation and student's activity on educational game. Int J Grid Distrib Comput 5(1)

25. Prensky M (2001) Digital game-based learning. McGraw-Hill, pp 9-34

26. Prensky M (2003) Digital game-based learning. In: Computers in entertainment, CIE

27. Qwaider WQ (October, 2011) Integrated of knowledge management and E-learning system. Int J Hybrid Inf Technol 4(4)

28. Radoff J (2011) Game on: energize your business with social media games. Wiley, pp 24-32

29. Rollings A, Morris D (2004) Game architect \& design, pp. 35-47, 59-62. New Riders

30. Strogatz SH (2000) Nonlinear dynamics and chaos. Perseus

31. Takahashi D (2008) Funware's threat to the traditional video game industry. Venturebeat

32. Verhulst PF (1838) Notice sur la loi que la population suit dans son accroissement. Corr Math Phys 10

33. Zichermann G, Cunningham C (2011) Gamification by design: implementing game mechanics in web and mobile apps. O'Reilly, pp 35-36

34. Zichermann G, Linder J (2010) Game-based marketing, pp. 19-20, 43-44. Wiley

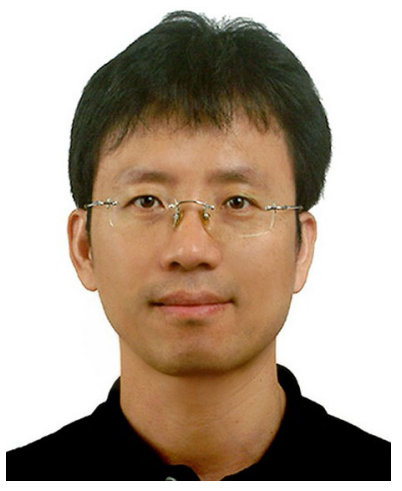

Jung Tae Kim is currently a full-time professor of Game Art \& Design Department, Hollywood School of Digital Arts at Shepherd University. His main research interests include the Gamification, convergence of digital art and technology, and mobile game engines. He has over 18 years experience as the game designer, producer and project manager at Samsung Electronics, G-star game show committee, and Game In USA corp. 


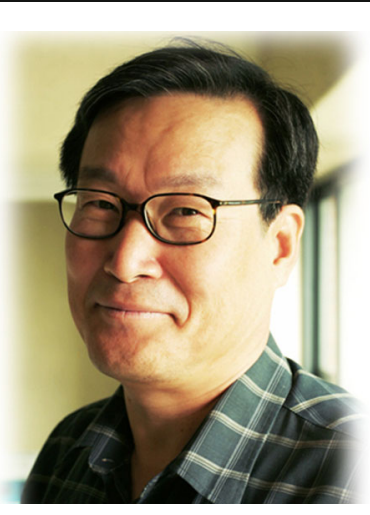

Won-Hyung Lee is currently a full-time professor of Image Engineering (Game) Department, Graduate School of Advanced Imaging Science, Multimedia \& Film, Chung-Ang University. Also he is the head of the Laboratory of Computer game \& Culture Technology. His current research fields include the convergence of art and digital technology, digital rights management and technology of game production 